\title{
Are uncomplicated type B aortic dissections truly uncomplicated?
}

\author{
Grayson H. Wheatley III, MD
}

From Siragusa Vascular, LLC, Nashville, Tenn

Disclosures: G.H.W. is a consultant for Medtronic, Terumo Aortic, Endologix, and Ethicon.

Received for publication June 5, 2018; revisions received June 5, 2018; accepted for publication June 6, 2018; available ahead of print July 11, 2018

Address for reprints: Grayson H. Wheatley III, MD, 28 White Bridge Pike, Suite 200, Nashville, TN 37205 (E-mail: ghw3rd@gmail.com).

J Thorac Cardiovasc Surg 2019;157:866-7

$0022-5223 / \$ 36.00$

Copyright (c) 2018 by The American Association for Thoracic Surgery

https://doi.org/10.1016/j.jtcvs.2018.06.005

Standard treatment guidelines for the management of uncomplicated type B aortic dissections (TBADs) dictate lifelong medical therapy with aggressive antihypertensive management and routine radiographic surveillance of the aortic dissection. ${ }^{1}$ However, a body of clinical evidence has emerged that suggests that certain radiographic features of the aorta along with distinct anatomic components of the aortic dissection-evident on initial presentation-can portend a more aggressive disease state with a greater likelihood of aortic degeneration over time. In this issue of the Journal, Shimamoto and colleagues ${ }^{2}$ report their findings regarding key anatomic predictors for increased likelihood of failure associated with medical therapy of uncomplicated TBAD.

The concept of being able to risk-stratify patients presenting with uncomplicated TBAD into a "high anatomic risk for future aortic degeneration" category or "low anatomic risk for future aortic degeneration" category is a novel one. Being able to assess which patients presenting with acute uncomplicated TBAD might require future aortic interventions helps physicians better optimize early treatment plans and ideally assist with preventing subsequent aortic-related deaths associated with long-term medical management of uncomplicated TBAD. Previous authors have identified anatomic variables in patients with uncomplicated TBAD, such as the size of the proximal entry tear, presence or absence of thrombus in the false lumen, and diameter of the false lumen as key predictors of future aortic-related mortality even in those patients optimally managed with medical therapy. 3,4

Careful analysis of 255 patients with uncomplicated TBAD in this study with 5-year follow-up demonstrated descending thoracic aortic diameter, false lumen thickness, and dilation of the abdominal aorta as independent risk factors for aortic events. ${ }^{2}$ It is becoming clear that uncomplicated TBAD is not a benign disease and that medical therapy is less effective in preventing future aortic-related deaths. ${ }^{5}$ As such, clinicians are seeking to identify key

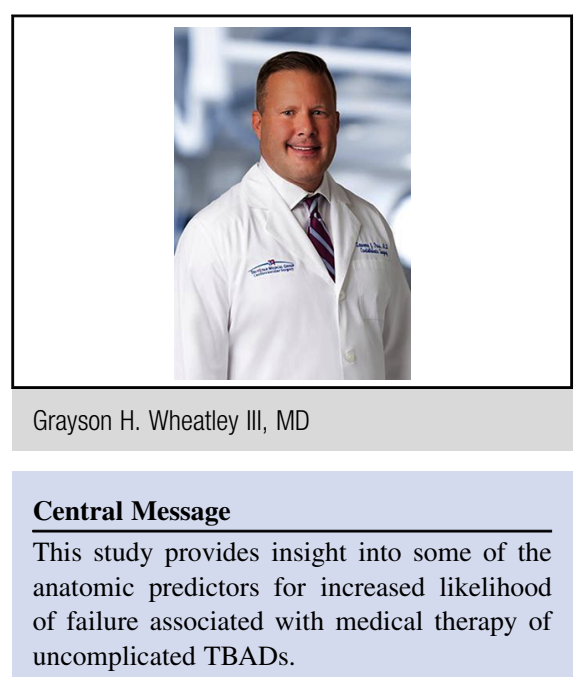

See Article page 854

markers of aortic anatomy in these patients. These key markers can help assist with early treatment intervention to prevent subsequent aneurysmal degeneration of the false lumen over time. The practice of intervening on all "asymptomatic" patients with uncomplicated TBAD early in the course of their disease to prevent future aortic-related mortality is not being recommended. However, it is clear that there are a subset of patients with uncomplicated TBAD who are at higher risk than other patients in developing aortic-related complications associated with their TBAD. The key is to clearly identify which anatomic factors are most relevant to justifying the surgical risk of performing an early intervention in an asymptomatic patient versus the known long-term aortic-related mortality associated with medical therapy for their TBAD.

Additional studies like this one are needed to definitely determine the risk factors associated with late aorticrelated mortality in TBAD. In the real world, most patients with uncomplicated TBAD have more than 1 high-risk anatomic feature, and future guidelines will rely on a scoring system of features to best identify the patients with the highest risk. In the end, uncomplicated TBAD is more complicated than we thought.

\section{References}

1. Fattori R, Cao P, De Rango P, Czerny M, Evangelista A, Nienaber C, et al. Interdisciplinary expert consensus document on management of type B aortic dissection. J Am Coll Cardiol. 2013;61:1661-78. 
2. Shimamoto T, Komiya T, Tsuneyoshi H. Fate of uncomplicated acute type B aortic dissection and impact of concurrent aortic dilation on remote aortic events. $J$ Thorac Cardiovasc Surg. 2019;157:854-63.

3. Tsai TT, Evangelista A, Nienaber CA, Myrmel T, Meinhardt G, Cooper JV, et al. Partial thrombosis of the false lumen in patients with acute type B aortic dissection. $N$ Engl J Med. 2007;357:349-59.
4. Reutersberg B, Trenner M, Haller B, Geisbüsch S, Reeps C, Eckstein HH. The incidence of delayed complications in acute type $\mathrm{B}$ aortic dissections is underestimated. J Vasc Surg. 2018;68:356-63.

5. Schwartz SI, Durham C, Clouse WD, Patel VI, Lancaster RT, Cambria RP, et al. Predictors of late aortic intervention in patients with medically treated type B aortic dissection. J Vasc Surg. 2018;67:78-84. 